\title{
The application of fuzzy Delphi and fuzzy inference system in supplier ranking and selection
}

\author{
Farzad Tahriri • Maryam Mousavi • \\ Siamak Hozhabri Haghighi · Siti Zawiah Md Dawal
}

Received: 23 November 2013/Accepted: 16 May 2014/Published online: 12 June 2014

(C) The Author(s) 2014. This article is published with open access at Springerlink.com

\begin{abstract}
In today's highly rival market, an effective supplier selection process is vital to the success of any manufacturing system. Selecting the appropriate supplier is always a difficult task because suppliers posses varied strengths and weaknesses that necessitate careful evaluations prior to suppliers' ranking. This is a complex process with many subjective and objective factors to consider before the benefits of supplier selection are achieved. This paper identifies six extremely critical criteria and thirteen sub-criteria based on the literature. A new methodology employing those criteria and sub-criteria is proposed for the assessment and ranking of a given set of suppliers. To handle the subjectivity of the decision maker's assessment, an integration of fuzzy Delphi with fuzzy inference system has been applied and a new ranking method is proposed for supplier selection problem. This supplier selection model enables decision makers to rank the suppliers based on three classifications including "extremely preferred", "moderately preferred", and "weakly preferred". In addition, in each classification, suppliers are put in order from highest final score to the lowest. Finally, the methodology is verified and validated through an example of a numerical test bed.
\end{abstract}

Keywords Supplier selection · Fuzzy Delphi method · Fuzzy inference system · Multiple-inputs multiple-output

F. Tahriri $(\bowtie) \cdot$ M. Mousavi · S. Zawiah Md Dawal Department of Mechanical Engineering, Faculty of Engineering, University of Malaya, 50603 Kuala Lumpur, Malaysia e-mail: farzad_tahriri@ hotmail.com

S. Hozhabri Haghighi

Department of Mechanical Engineering, Shiraz University, 71936 Shiraz, Iran

\section{Introduction}

One of the important decisions which play a major role in alleviation of the total cost in manufacturing systems is the effective supplier selection (Liu and Hai 2005). The selection process of vendors would be a simple task if only one criterion is used in decision making process. However, in real situation, purchasers have to consider a range of criteria to finalize their decisions. When several criteria are used, it is necessary to specify how much each criterion affects the decision-making procedure; they can be equally weighted or weights could be varied based on the type of criteria (Yahya and Kingsman 1999). According to Tahriri and Taha (2010) studies, some difficulties regarding supplier selection are included: (1) huge variety of finished products, and thus a great need for purchasing a raw material, (2) the large number of projects in process by factories, (3) the huge fluctuations in price for purchasing the raw materials, (4) the large number of suppliers by varieties of qualitative and quantitative criteria. In the same vein, Chen-Tung and Ching-Torng (2006) studied the group multiple criteria decision-making (MCDM) approach for supplier selection problem using quantity criteria. In MCDM, a problem is affected by a number of conflicting factors in supplier selection, for which a purchasing manager must analyze the tradeoff among the several criteria. MCDM techniques support the decision-makers in evaluating a set of alternatives. Depending on purchasing situations, criteria have variable importance that necessitates the weighting process (Dulmin and Mininno 2003).

In the supplier selection context, many multi-criteria decision making methods have been applied such as fuzzy TOPSIS, analytic network process (ANP), data envelopment analysis (DEA), analytic hierarchy process (AHP), and mathematical programming (Wu and Olson 2008; 
Kheljani et al. 2009; Lin et al. 2011; Bhattacharya et al. 2010; Moghadam et al. 2008; Wang et al. 2009; Liu and Hai 2005; Yusuff et al. 2001; Tam and Tummala 2001; Yu and Jing 2004). Another approach that can be evaluated and applied to the supplier-selection decision making process is a technique that integrates integer programming, goal programming, stochastic method, fuzzy set theory, and fuzzy multiple attribute decision making (FMADM) into a one inclusive approach. FMADM addresses the problem of choosing an alternative from a set of alternatives that are characterized according to their attributes (Tahriri et al. 2008a). The MADM method helps the manufacturer to incorporate the uncertainty of the future resulting from multi-objectivity and introduce subjective criteria in the modeling phase. On the other hand, it requires more data, and it is usually more complex than the economic analysis. Referring to the Amindoust et al. (2012) study, which proposes a fuzzy inference system (FIS) for supplier selection, the subjectivity of decision makers' assessments are handled and the feasibility of the proposed method is shown by utilization of an illustrative example. Junior et al. (2013) proposed a new model based on fuzzy logic to handle the various attributes associated with supplier evaluation problems. Four multi-input multiple-output (MIMO) Mamdani FIS have been proposed for supplier evaluation. The proposed model has been illustrated through a case study.

Table 1 presents the description of some of the most widely used methods for supplier selection. Additionally, as FD and FIS are the methods, which are used in this paper, they will be given extra focus and further explanations. FIS represent an important part of fuzzy logic. In particular, the main advantages are the interpretation capability and the ease of encoding a priori knowledge; whereas the main limitation is the lack of learning capabilities compared with other methods. The fuzzy Delphi method (FDM), an integration of the fuzzy concept and the Delphi method, requires only a small survey sample to obtain an objective and reasonable result. With this method, time and costs of collecting questionnaires can be reduced, and experts' opinion can be kept as they are without being twisted (Cheng and Tang 2009). The FD and FIS methods have their own advantages, by integrating these two methods the feasibility and accuracy of the model is increased.

An attempt has been made in this paper to identify the most important critical factors in order to select a suitable supplier through the literature. Then, a new fuzzy set multiple criteria decision-making (FMCDM) approach is proposed by integrating fuzzy Delphi (FD) and FIS to categorize the suppliers under three classifications including "extremely preferred", "moderately preferred", and "weakly preferred". Moreover, the suppliers under each group are also put in order by the highest final score to the lowest.

\section{Determination of the supplier selection indicators}

The identification of the critical factors in selecting an appropriate supplier is the first main step in developing the model. According to previous research Ho et al. (2010), Tahriri et al. (2008b), and Tahriri et al. (2008a), thirteen criteria have been identified in supplier selection as shown in Table 2. These criteria are categorized under six aspects such as trust, quality, cost, delivery, management and organization, and financial.

\section{Development of supplier evaluation and selection}

The objective of this research is to develop a supplier evaluation and selection model. In this regard, a two-phase method with procedures are proposed. The first step used FDM to obtain the weight for critical factors of the model by decision maker to select the best supplier. In the second step, FIS method is applied to evaluate and select the appropriate supplier. Figure 1 shows the fuzzy decision making system (FDMS) structure. The numerical test bed example by considering the qualitative and quantitative criteria has been made to test the model.

Table 3 shows a procedure of the multi-criteria decision making model for evaluating and selecting the best supplier by using an integration of qualitative and quantitative criteria.

Fuzzy Delphi method

\section{Defining aspects and criteria for hierarchical structure}

Numerous criteria can be considered in a multi-criteria evaluation problem. These criteria should be identified under each of the $k$ criteria $\left(C_{1}, C_{2}, \ldots, C_{h}, C_{h+1}, \ldots, C_{k}\right)$ considering the specific requirements of the problem. The criteria can be classified into two categories: (1) subjective criteria, $C_{1}, C_{2}, \ldots, C_{h}$; these criteria have a linguistic/ qualitative definition; (2) objective criteria, $C_{h+1}$, $C_{h+2}, \ldots, C_{k}$; these criteria are defined in monetary/quantitative terms. Based on the aspects these criteria were used to construct the hierarchy of the primary model.

\section{Fuzzy Delphi method to adjust the consensus condition}

Fuzzy Delphi method derived from fuzzy set theory and traditional Delphi technique is proposed by Ishikawa (1993). Noorderhaben (1995) suggested that the solution to the Fuzziness of common understanding, based on the expert's opinions, can be performed by applying the FDM to a group decision. The application of the FDM forms a set of weights for a variety of criteria. For assessing and 
Table 1 Comparison of the supplier selection methods

\begin{tabular}{|c|c|c|}
\hline Method & Advantages & Disadvantages \\
\hline Cost ratio & $\begin{array}{l}\text { Subjectivity is reduced } \\
\text { Flexibility }\end{array}$ & $\begin{array}{l}\text { Complexity and requirement for a developed cost accounting } \\
\text { system } \\
\text { Performance measures (cost ratios) are artificially expressed } \\
\text { in the same units }\end{array}$ \\
\hline $\begin{array}{l}\text { Principal } \\
\text { Component } \\
\text { analysis (PCA) }\end{array}$ & $\begin{array}{l}\text { Considers simultaneously multiple inputs and outputs } \\
\text { without priori assignment of weights }\end{array}$ & Knowledge of advanced statistical methods is required \\
\hline $\begin{array}{l}\text { Artificial neural } \\
\text { network (ANN) }\end{array}$ & Saves a lot of time and money of system development & $\begin{array}{l}\text { Lack of expertise } \\
\text { Requires a software }\end{array}$ \\
\hline $\begin{array}{l}\text { Analytic } \\
\text { hierarchical } \\
\text { process (AHP) }\end{array}$ & $\begin{array}{l}\text { Simplicity } \\
\text { Captures both qualitative and quantitative criteria } \\
\text { Forces managers make trade-offs } \\
\text { Use in both criteria comparison and individual aspects } \\
\text { within each criterion can be tackled }\end{array}$ & $\begin{array}{l}\text { Inconsistency on the method } \\
\text { Require enumerations of all issues } \\
\text { Require intense management involvement }\end{array}$ \\
\hline $\begin{array}{l}\text { Multiple attribute } \\
\text { utility theory } \\
\text { (MAUT) }\end{array}$ & $\begin{array}{l}\text { Purchasing professionals to formulate viable sourcing } \\
\text { strategies } \\
\text { Capable of handling multiple conflicting attribute }\end{array}$ & $\begin{array}{l}\text { Just used for international supplier selection, where the } \\
\text { environment is more complicated and risky }\end{array}$ \\
\hline $\begin{array}{l}\text { Activity-based } \\
\text { costing (ABC) }\end{array}$ & $\begin{array}{l}\text { Categorizing costs into } \mathrm{ABC} \text { categories and then making a } \\
\text { selection based on the criteria selected }\end{array}$ & $\begin{array}{l}\text { ABC method is the method, which is most focused on cost } \\
\text { ABC is decided base on how frequently the activity is } \\
\text { performed in support of these cost objects } \\
\text { When cost categories are part of the criteria }\end{array}$ \\
\hline $\begin{array}{l}\text { Total cost of } \\
\text { ownership } \\
\text { (TCO) }\end{array}$ & $\begin{array}{l}\text { Substantial cost savings } \\
\text { Allows various purchasing policies to be compared with one } \\
\text { another }\end{array}$ & $\begin{array}{l}\text { Complex } \\
\text { Require extensive tracking and maintenance of cost data } \\
\text { Requires cultural change often situation specific }\end{array}$ \\
\hline Categorical & $\begin{array}{l}\text { The evaluation process is clear and systematic } \\
\text { Inexpensive } \\
\text { Requires a minimum Performance data }\end{array}$ & $\begin{array}{l}\text { Attributes are weighted equally } \\
\text { Subjective } \\
\text { Imprecise }\end{array}$ \\
\hline Weighted point & Attributes are weighted by importance & $\begin{array}{l}\text { Subjective } \\
\text { Difficult to effectively consider qualitative criteria }\end{array}$ \\
\hline Fuzzy TOPSIS & $\begin{array}{l}\text { Simple, rationally comprehensible concept } \\
\text { Good computational efficiency } \\
\text { Ability to measure the relative performance for each } \\
\text { alternative in a simple mathematical form }\end{array}$ & $\begin{array}{l}\text { A disadvantage is that its use of Euclidean distance does not } \\
\text { consider the correlation of attributes } \\
\text { Difficult to weight attributes and keep consistency of } \\
\text { judgment, especially with additional attributes }\end{array}$ \\
\hline Fuzzy ANP & $\begin{array}{l}\text { Selection of best suitable alternative by considering various } \\
\text { interdependent values across the supply chain and also } \\
\text { overcome vagueness associated with the computation }\end{array}$ & $\begin{array}{l}\text { The interdependence among the factors must be analyzed } \\
\text { first to reduce the number of pairwise comparisons, which } \\
\text { is one of most often-mentioned disadvantage }\end{array}$ \\
\hline Fuzzy Delphi & $\begin{array}{l}\text { Saving time in obtaining results } \\
\text { Reducing number of surveys required } \\
\text { Increases questionnaire recovery rate } \\
\text { By applying the fuzzy theory to clarify invertible fuzziness } \\
\text { in interviews with experts to obtain more reasonable and } \\
\text { proper responses } \\
\text { Achieving higher economic effectiveness in time and costs } \\
\text { required to conduct surveys } \\
\text { Simple calculation process, handling multi-level, multi- } \\
\text { attribute, and multi-solution decision problems } \\
\text { Experts can fully express their opinions, ensuring the } \\
\text { completeness and consistency of the group opinion } \\
\text { Lower cost, and saves survey time }\end{array}$ & $\begin{array}{l}\text { Takes into account the fuzziness that can't be avoided during } \\
\text { the survey process } \\
\text { Does not misinterpret experts' original opinions and } \\
\text { provides a true reflection of their response }\end{array}$ \\
\hline $\begin{array}{l}\text { Fuzzy inference } \\
\text { system }\end{array}$ & $\begin{array}{l}\text { Interpretation capability } \\
\text { The ease of encoding a priori knowledge }\end{array}$ & Lack of learning capabilities \\
\hline
\end{tabular}




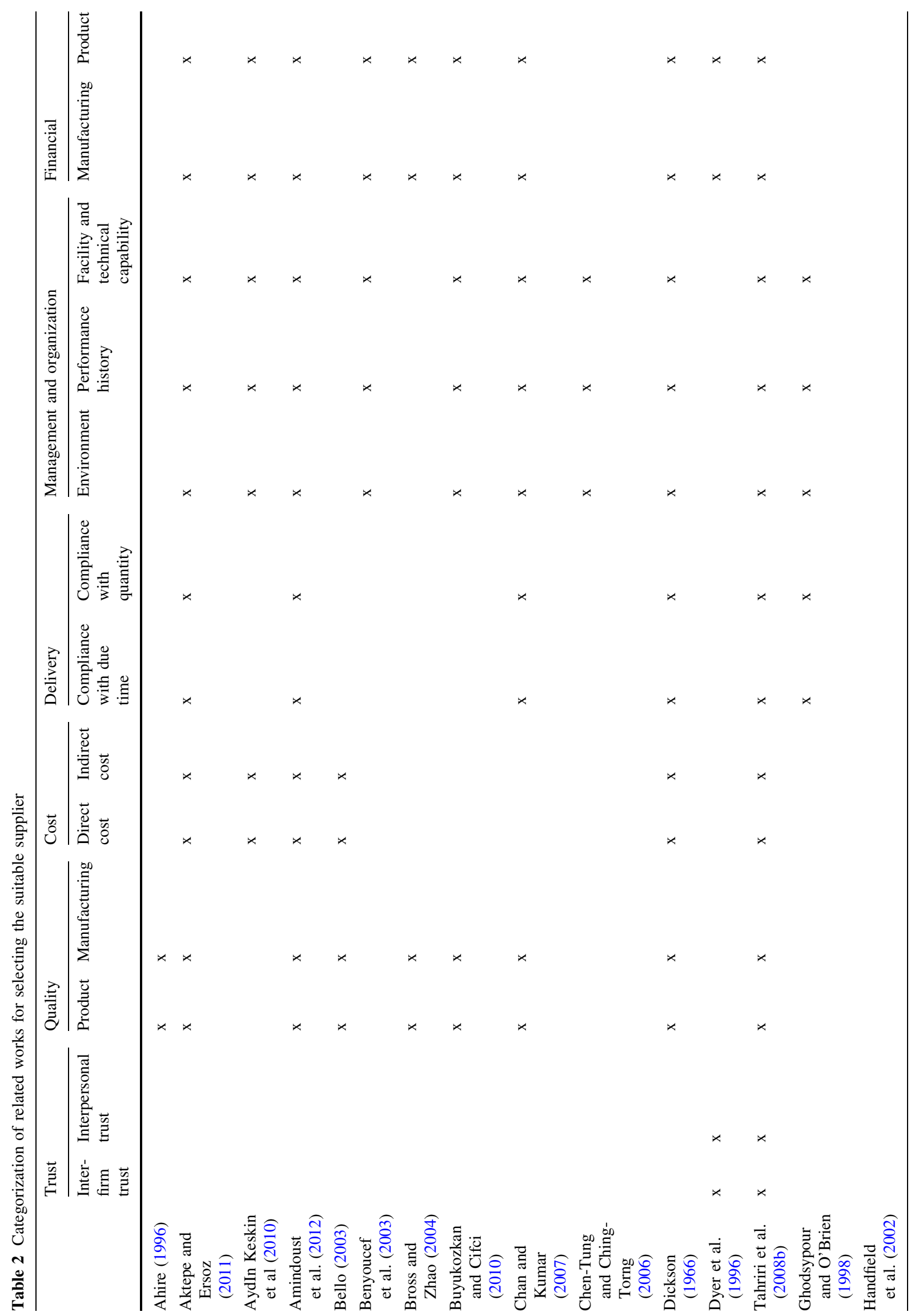




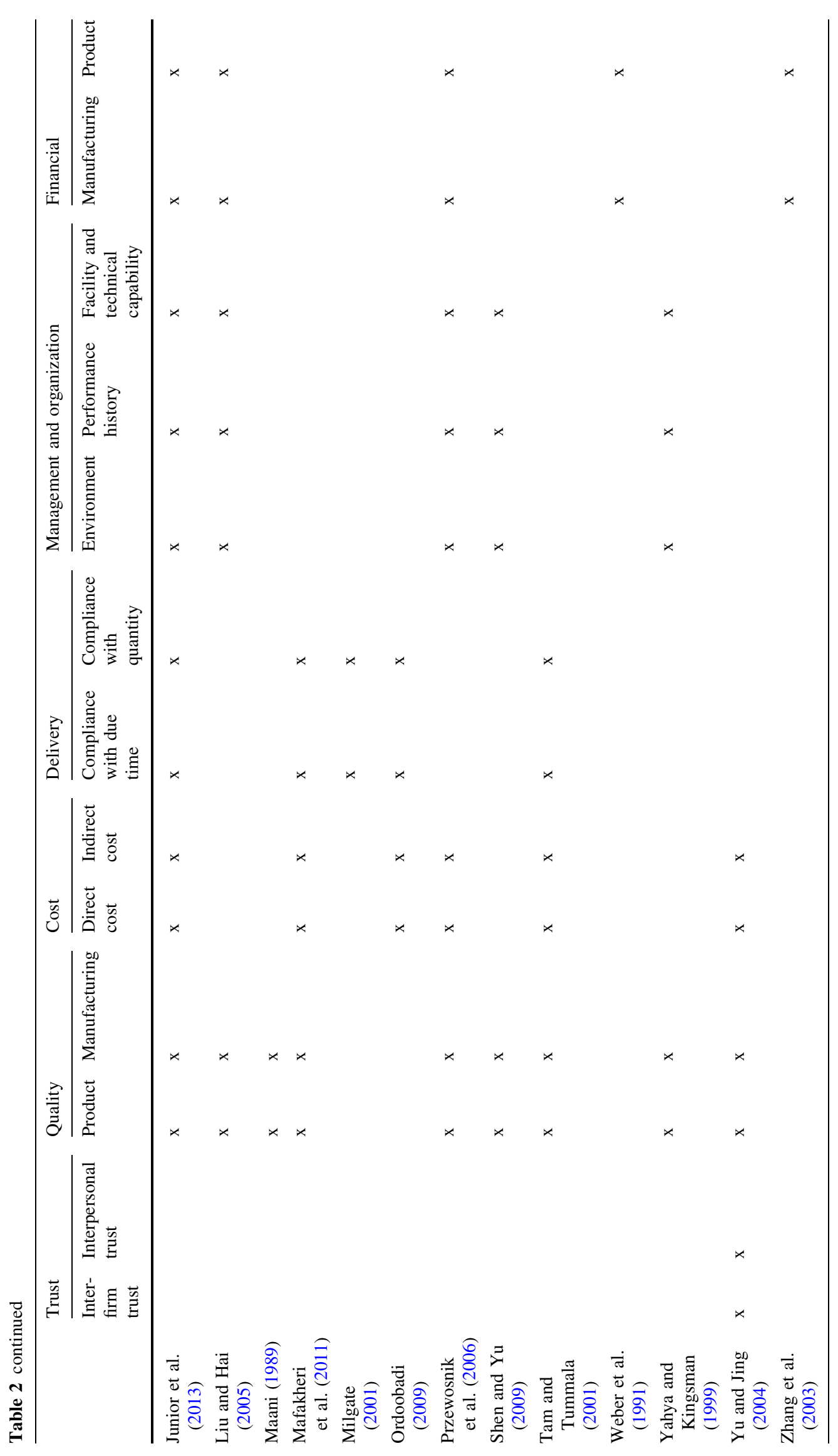




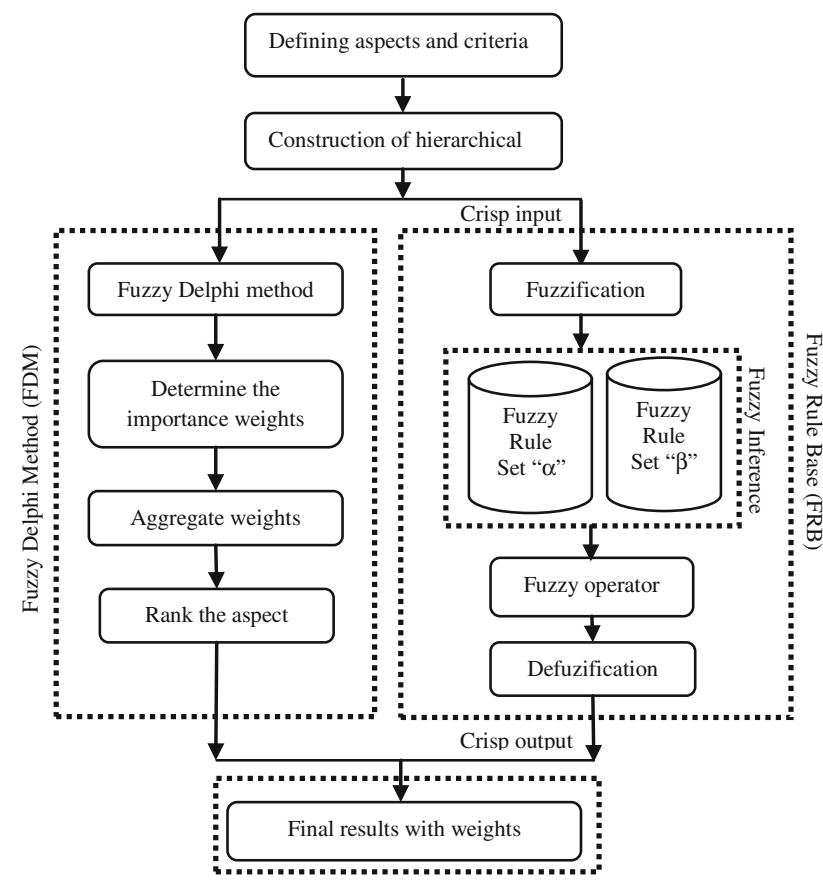

Fig. 1 Fuzzy decision making system (FDMS) structure

Table 3 The success supplier selection procedure

\begin{tabular}{|c|c|}
\hline Step 1: & Defining aspects and criteria \\
\hline Step 2: & Construction of hierarchical structure \\
\hline Step 3: & $\begin{array}{l}\text { Using the fuzzy Delphi method to evaluate the importance } \\
\text { weight of each aspect based on the group decision makers }\end{array}$ \\
\hline Step 4: & $\begin{array}{l}\text { Determine the importance weights for each aspect based on } \\
\text { the linguistic scales }\end{array}$ \\
\hline Step 5: & $\begin{array}{l}\text { Transfer linguistic terms of positive triangular fuzzy } \\
\text { numbers }\end{array}$ \\
\hline Step 6: & $\begin{array}{l}\text { Aggregate the mean of fuzzy weights for each aspect }\left(W_{t}\right) \text {, } \\
\text { then calculate the deffuzification of fuzzy suitability index } \\
\text { values for each aspect }\end{array}$ \\
\hline Step 7: & Rank the aspect based on the $\alpha$-cut set \\
\hline Step 8: & Design the membership function \\
\hline Step 9: & Design the fuzzy rule set \\
\hline $\begin{array}{l}\text { Step } \\
10:\end{array}$ & Fuzzy operator \\
\hline $\begin{array}{l}\text { Step } \\
11:\end{array}$ & Defuzzification \\
\hline $\begin{array}{l}\text { Step } \\
12:\end{array}$ & $\begin{array}{l}\text { Calculate the overall mean of defuzzification of fuzzy rule } \\
\text { base evaluation rating }\left(X_{t}\right) \text { and weighting the fuzzy Delphi } \\
\left(W_{t}\right) \text { for each criteria and aspect }\end{array}$ \\
\hline
\end{tabular}

evaluating the performance rating, comprising the importance and appropriateness of linguistic variation, the concept of triangular fuzzy number and linguistic variables are used. Although Delphi is an expert opinion survey method having three features: Anonymous response, Iteration and controlled feedback and finally the statistical group response. Some weaknesses manifested, that block forecasting values to converge. Thus, repetitive surveys are required to perform the action which leads to needing much more time and cost (Ishikawa 1993; Wang 2008).

Delphi method provides easy understanding of the group opinions through the twice provision of the questionnaire. Since FDM integrates the fuzzy theory with the FDM, it provides the user with the advantage of Delphi method and reduction of the questionnaire time and cost (Hsu 2010; Yu-Feng 2008).

The triangular membership functions and the fuzzy theory are applied in this paper to solve the group decisions and screen the attributive factors of the first stage by using FDM. Applying the fuzzy theory can solve and evaluate the fuzziness of common understanding of experts on a variety of scales.

The FDM steps are as follows:

Collecting opinions of decision group the expert's opinions are described by linguistic terms, which can be expressed in triangular fuzzy numbers, to make the consensus of the experts consistent. A committee of $n$ decision-makers $\left(D_{1}, D_{2}, \ldots, D_{n}\right)$ evaluates the $k$ criteria and assigns a suitable weight to each one based on their importance. The committee uses linguistic weighting variables in their assessment (Zadeh 1975). Given weights are very low $(V L)$, low $(L)$, medium $(M)$, high $(H)$, and very high $(V H)$ importance. The linguistic weighting variables and the linguistic scale variables can be transformed into triangular fuzzy numbers. The membership functions for important weights are shown in Fig. 2 and Table 4, respectively.

Setting up triangular fuzzy numbers the triangular fuzzy number of each factor is calculated, evaluated, and obtained based on the value given by experts.

Aggregation of experts' opinion in this step, FDM is used to aggregate the decision makers' given weights to each criteria and obtain a mean fuzzy weight under consensus condition. To this end, fuzzy numbers operations are utilized to achieve the mean of weight $\left(W_{t}\right)$ and transfer linguistic terms to positive trapezoidal fuzzy numbers. Suppose that $W_{t}$ is the linguistic weight given to subjective criteria $C_{1}, C_{2}, \ldots, C_{k-s}$, and objective criteria $C_{k-s+1}, \ldots$, $C_{k}$ by decision maker $D_{j}$. The aggregation is formulated as below:

$$
\begin{aligned}
\mathrm{D}_{i j} & =(1 / m) \otimes\left(\mathrm{D}_{i j}^{1} \oplus \mathrm{D}_{i j}^{2} \oplus \ldots \oplus \mathrm{D}_{i j}^{m}\right), \\
t & =1,2, \ldots, k
\end{aligned}
$$

where, $\otimes$ is the multiplication of fuzzy numbers, $\oplus$ is the add operation of fuzzy numbers, and $D_{i j}$ is the overall average weighting valuation of alternative $i$ under criterion $j$ over $m$ assessors.

As shown in Eq. 2, $D_{i j}$ as a fuzzy number can be represented by the triangular membership. 


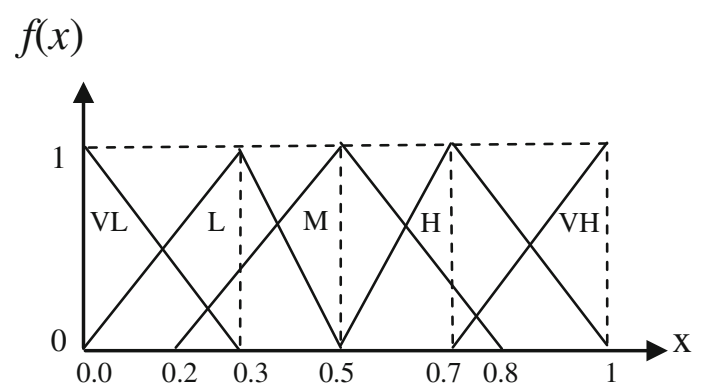

Fig. 2 Membership function for importance weight of criteria

Table 4 linguistic variables and fuzzy numbers for the importance weight

\begin{tabular}{lc}
\hline Linguistic variables & Fuzzy numbers \\
\hline Very low (VL) & $(0.0,0.0,0.3)$ \\
Low (L) & $(0.0,0.3,0.5)$ \\
Medium (M) & $(0.2,0.5,0.8)$ \\
High (H) & $(0.5,0.7,1.0)$ \\
Very high (VH) & $(0.7,1.0,1.0)$ \\
\hline
\end{tabular}

$D_{i j}=\left(\mathrm{LD}_{i j}, \mathrm{MD}_{i j}, \mathrm{UD}_{i j}\right)$

Then the fuzzy weighting $\tilde{W}_{t}$ of $j$ element is $\tilde{W}_{t}=$ $\left(a_{t}, b_{t}, c_{t}\right), t=1,2, \ldots, k$. Among which

$$
\begin{aligned}
& \mathrm{LD}_{i j}=\left(\sum_{i j}^{m} \mathrm{LD}_{i j}^{k}\right) / m, \mathrm{MD}_{i j}=\left(\sum_{k=1}^{m} \mathrm{MD}_{i j}^{k}\right) / m, \\
& \mathrm{UD}_{i j}=\left(\sum_{k=1}^{m} \mathrm{UD}_{i j}^{k}\right) / m
\end{aligned}
$$

Finally, the result of fuzzy synthetic decision weighting of each criteria is a fuzzy number. Thus, non-fuzzy ranking method for fuzzy numbers needs to be employed for each criterion. Converting fuzzy numbers into real value numbers is a technique called defuzzification, which locates the best non fuzzy performance (BNP) value. Center-of-area defuzzification method does not require analyst's personal judgment as it is based on simplicity. The defuzzified value of fuzzy number can be obtained from Eq. 4.

$$
\begin{aligned}
\mathrm{BNP}_{i j}= & {\left[\left(\mathrm{UD}_{i j}-\mathrm{LD}_{i j}\right)+\left(\mathrm{MD}_{i j}-\mathrm{LD}_{i j}\right)\right] / 3 } \\
& +\mathrm{LD}_{i j} \forall i, j .
\end{aligned}
$$

Fuzzy inference system

\section{Fuzzifier}

The input variable $(x)$ of the fuzzy logic is real numerical value limited to the domain of discourse $(X)$ and the output an interval between 0 and 1 is a fuzzy degree in the qualifying linguistic set $\left[\mu_{\tilde{A}}(x)\right]$. By fuzzification the crisp input values are transformed into fuzzy sets. A fuzzy set $\tilde{A}=(a, b, c, d)$ in a domain $X$ is called a normal fuzzy set if $\Leftarrow \mathrm{x}_{\mathrm{i}} \varepsilon X, \mu_{\tilde{A}}\left(x_{i}\right)=1$. A fuzzy number is a fuzzy set in the domain of discourse $\mathbb{R}$ ( $\mathbb{R}$ is a set of real numbers) that is convex and normal. A fuzzy set $\tilde{A}$ in the domain $\mathbb{R}$ is called a fuzzy trapezoidal number, with a core $[b, c]$, the left width $\delta=\mathrm{b}-\mathrm{a}$, the right width $\beta=\mathrm{d}-\mathrm{c}$, if its membership function exhibits the shape represented by Eq. 5 and Fig. 3, (Keufmann 1991):

$$
\mu_{\tilde{A}}(x)=\left\{\begin{array}{lc}
0 & x<a, \\
1-\frac{b-x}{b-a} & a<x \leq b, \\
1 & b<x \leq c, \\
1-\frac{x-c}{d-c} & c<x \leq d, \\
0 & d<x
\end{array}\right.
$$

where $a \leq b \leq c \leq d$ and $a, b, c, d \varepsilon \mathbb{R}$. A fuzzy trapezoidal number $\tilde{A}$ can be characterized by the ordered quadruple $\tilde{A}=(a, b, c, d)$, and can be interpreted as a fuzzy quantity " $x$ is approximately in the interval $[b, c]$ ", i.e., as approximate, fuzzy interval. Constants " $c$ " and " $d$ " are the lower and upper bounds of the available area for the evaluation data. These constants reflect the fuzziness of the evaluation data. Fuzzy set is a class with a continuum of grades of membership. Let $X$ be a nonempty set, a domain of discourse where $X=\left\{x_{1}, x_{2}, \ldots, x_{n}\right\}$. A fuzzy (sub) set $\tilde{A}$ of a domain of discourse $\mathrm{X}$ is a set of ordered pairs

$$
\begin{aligned}
\tilde{A}= & \left\{\left(x_{1}, \mu_{\tilde{A}}\left(x_{1}\right)\right),\left(x_{2}, \mu_{\tilde{A}}\left(x_{2}\right)\right), \ldots,\left(x_{n}, \mu_{\tilde{A}}\left(x_{n}\right)\right)\right. \\
& \left.\mid x_{1}, x_{2}, \ldots, x_{n} \in X\right\},
\end{aligned}
$$

$\mu_{\tilde{A}}: X \rightarrow[0,1]$,

where $\mu_{\tilde{A}}$ is a membership function or grade of a fuzzy set $\tilde{A}, \mu_{\tilde{A}}(x): X \rightarrow[0,1]$, in an accepting mathematical notation. A membership function $\mu_{\tilde{A}}\left(x_{i}\right)$ gives the membership degree of a generic element $x_{i}$ to the fuzzy set $\tilde{A}$. Trapezoidal fuzzy numbers are the most widely used forms of fuzzy numbers because they can be handled arithmetically and interpreted intuitively. Therefore, trapezoidal fuzzy numbers are used in this study. The MIMO FIS is used. The values of the inputs and multi separated output variables are measured and transferred to the range of the corresponding universe of discourse, which converts them into associated values.

The development of membership functions for the supplier performance criteria using fuzzy input and output variables for each aspect are formulated for this research based on the discussions with the experts. All the membership function variables are trapezium. Four fuzzy sets in 


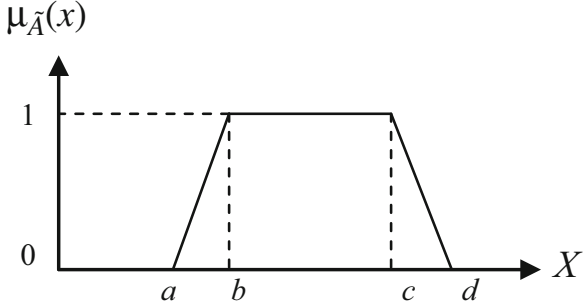

Fig. 3 A fuzzy trapezoidal number $\tilde{A}$

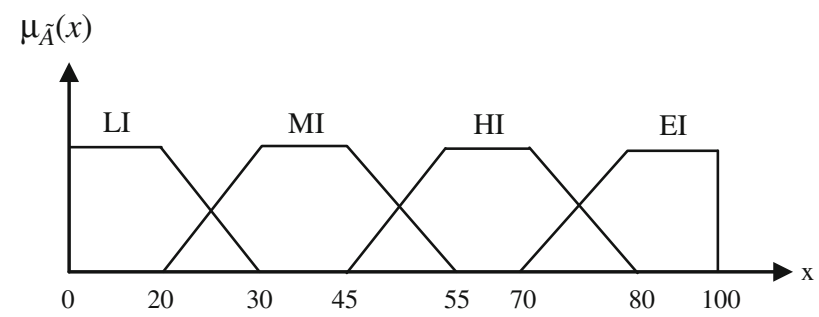

Fig. 4 The membership function for the supplier performance criteria

Table 5 The linguistic weighting terms of input variables

\begin{tabular}{ll}
\hline Description & Assigned weights \\
\hline Low importance (LI) & $(0,0,20,30)$ \\
Moderate importance (MI) & $(20,30,45,55)$ \\
High importance (HI) & $(45,55,70,80)$ \\
Extreme importance(EI) & $(70,80,100,100)$ \\
\hline
\end{tabular}

the form of linguistic weighting variables, which include "Low Importance (LI)", "Moderate Importance (MI)", "High Importance (HI)" and "Extreme Importance (EI)", were utilized to evaluate the importance of input variables (Fig. 4; Table 5).

Three fuzzy sets in the form of linguistic weighting variables, which include "Weakly preferred (WP)", "Moderately preferred (MP)" and "Extremely preferred (HP)" were utilized to evaluate the importance of output variables. These variables are equivalent to fuzzy numbers on the numeric scale $0-1$. Figure 5 presents the three fuzzy sets and the linguistic weighting variables as shown in Table 6.

\section{Fuzzy rule set}

After determining the fuzzification, the input data with the conditions of the rules are determined and evaluated. There is a degree of membership for each linguistic term that applies to that input variable. The essential part of fuzzy

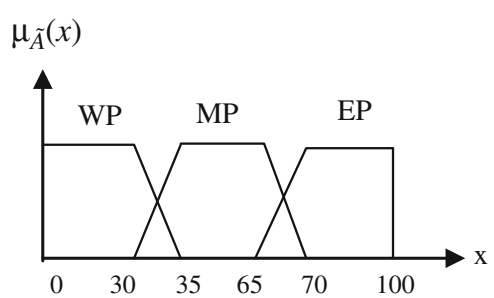

Fig. 5 The membership function for ranking the supplier

Table 6 The linguistic weighting terms of output variables

\begin{tabular}{ll}
\hline Description & Assigned weights \\
\hline Weakly preferred (WP) & $(0,0,30,35)$ \\
Moderately preferred (MP) & $(30,35,65,70)$ \\
Extremely preferred (EP) & $(65,70,100,100)$ \\
\hline
\end{tabular}

rule based systems (FRBSs) is a set of IF-THEN linguistic rules, that have the general form "IF A THEN B" where $A$ and $B$ are (collections of) propositions containing linguistic variables.

In fuzzy rules (FLs), connectives such as AND and OR, are commonly used to relate two or more antecedents. In a more explicit form, if there are $i$ rules $\left(R_{i}\right)$ each with $k$ premises in a system, the $i$ th rule has the following form.

$R_{i}:$ If $X_{i 1}$ is $A_{i 1}$ and $X_{i 2}$ is $A_{i 2} \ldots$ and $X_{i k}$ is $A_{i k}$ then $Y$ is $B_{i}$

In the above equation, $X$ represents the crisp inputs to the rule and $A_{i}$ and $B_{i}$ are linguistic variables, also $X_{i 1}$ to $X_{i k}$ and $Y$ being the input and output variables for regression respectively. The minimum value of the input variables' membership values is based on the membership value of the control action of each rule. The number of FLs used in controlling the system using fuzzy control is represented by

$N=\sum_{j=1}^{m}\left(\prod_{i=1}^{n} L_{i}\right)$

where $N$ is the total number of rules required in controlling the system, $m$ the number of the sets of rules using one set of variables, $n$ the number of input variables used in a set of rules and $L$ the number of fuzzy sets (labels) in an input (i) variable.

The if-then rules for the related FIS engines are designed based on a number of input variable of each aspect by using expert knowledge. These rules are based on the linguistic variables defined in the fuzzification of the input data. Numerous rules are needed to replicate expert knowledge. When combined, the rules integrate much of this knowledge into the fuzzy rule-based expert system. The rules, thus create what we refer to as the knowledge 
Table 7 Fuzzy if-then $\alpha$ rule

\begin{tabular}{lllll}
\hline Input 2 & \multicolumn{2}{l}{ Input 1} \\
\cline { 2 - 5 } & LI & MI & HI & EI \\
\hline LI & LI & LI & MI & MI \\
MI & LI & MI & MI & HI \\
HI & MI & MI & HI & HI \\
EI & MI & HI & HI & EI \\
\hline
\end{tabular}

base (Baetge and Heitmann 2000). The number of rules for each aspect is calculated separately, based on each rule name including $\alpha$ and $\beta$. The rules for the second, third input variables are using rules $\alpha, \beta$ as shown in Tables 7,8 . If the number of aspect input variables is great, the fix rules based on the input number of variables can be applied. This method can help the expert to design the rules easily, and precisely provide the required response and more because the number of rules of each aspect is limited.

\section{Fuzzy operator}

Addition and multiplication of fuzzy operations are utilized in our model. Suppose Eqs. 8 and 9 are two trapezoidal fuzzy numbers as

$R=\left(r_{1}, r_{2}, r_{3}, r_{4}\right)$

$S=\left(s_{1}, s_{2}, s_{3}, s_{4}\right)$

Therefore, addition and multiplication of them are as follows respectively.
$R+S=\left(r_{1}+s_{1}, r_{2}+s_{2}, r_{3}+s_{3}, r_{4}+s_{4}\right)$

$R * S=\left(r_{1} * s_{1}, r_{2} * s_{2}, r_{3} * s_{3}, r_{4} * s_{4}\right)$

\section{Defuzzification}

A set of rules is applied to the fuzzified input, which is scalar in value, with the output of each rule being Fuzzy. In order for the nature of the action to be determined by the system, these fuzzy outputs should be converted to scalar quantity, the process of which is called defuzzification. The input for the defuzzification process is a fuzzy set (the aggregate output fuzzy set) and the output is a single number. The centroid calculation, which returns the center of gravity under the curve, can be the most popular example of defuzzification. This technique was developed by Sugeno in 1985, which is the most commonly used and accurate, and can be expressed as:

$X^{*}=\frac{\int \mu_{i}(x) x \mathrm{~d} x}{\int \mu_{i}(x) \mathrm{d} x}$

where $X^{*}$ is the defuzzified output, $\mu_{i}(x)$ the aggregated membership function and $x$ the output variable. The only disadvantage of this method is that it is computationally difficult for complex membership functions.

Fuzzy Delphi multi attribute decision making

To determine the final result-based on the weights assigned to each aspect and the values assigned to each

Table 8 Fuzzy if-then $\beta$ rule

\begin{tabular}{|c|c|c|c|c|c|c|c|c|c|c|c|c|c|c|c|c|c|c|c|}
\hline \multirow[t]{2}{*}{$\begin{array}{l}\text { Rule } \\
\text { no. }\end{array}$} & \multicolumn{3}{|c|}{$\begin{array}{l}\text { Fuzzy input } \\
\text { variables }\end{array}$} & \multirow{2}{*}{$\begin{array}{l}\text { Fuzzy } \\
\text { output } \\
\text { variables }\end{array}$} & \multirow[t]{2}{*}{$\begin{array}{l}\text { Rule } \\
\text { no. }\end{array}$} & \multicolumn{3}{|c|}{$\begin{array}{l}\text { Fuzzy input } \\
\text { variables }\end{array}$} & \multirow{2}{*}{$\begin{array}{l}\text { Fuzzy } \\
\text { output } \\
\text { variables }\end{array}$} & \multirow[t]{2}{*}{$\begin{array}{l}\text { Rule } \\
\text { no. }\end{array}$} & \multicolumn{3}{|c|}{$\begin{array}{l}\text { Fuzzy input } \\
\text { variables }\end{array}$} & \multirow{2}{*}{$\begin{array}{l}\text { Fuzzy } \\
\text { output } \\
\text { variables }\end{array}$} & \multirow[t]{2}{*}{$\begin{array}{l}\text { Rule } \\
\text { no. }\end{array}$} & \multicolumn{3}{|c|}{$\begin{array}{l}\text { Fuzzy input } \\
\text { variables }\end{array}$} & \multirow{2}{*}{$\begin{array}{l}\text { Fuzzy } \\
\text { output } \\
\text { variables }\end{array}$} \\
\hline & 1 & 2 & 3 & & & 1 & 2 & 3 & & & 1 & 2 & 3 & & & 1 & 2 & 3 & \\
\hline 1 & LI & LI & LI & LI & 17 & MI & LI & LI & LI & 33 & HI & LI & LI & MI & 49 & MI & LI & LI & LI \\
\hline 2 & LI & MI & LI & LI & 18 & MI & MI & LI & MI & 34 & HI & MI & LI & MI & 50 & MI & MI & LI & MI \\
\hline 3 & LI & $\mathrm{HI}$ & LI & LI & 19 & MI & $\mathrm{HI}$ & LI & MI & 35 & HI & HI & LI & MI & 51 & MI & HI & LI & MI \\
\hline 4 & LI & EI & LI & LI & 20 & MI & EI & LI & MI & 36 & HI & EI & LI & MI & 52 & MI & EI & LI & MI \\
\hline 5 & LI & LI & MI & LI & 21 & MI & LI & MI & MI & 37 & $\mathrm{HI}$ & LI & MI & MI & 53 & MI & LI & MI & MI \\
\hline 6 & LI & MI & MI & MI & 22 & MI & MI & MI & MI & 38 & HI & MI & MI & MI & 54 & MI & MI & MI & MI \\
\hline 7 & LI & $\mathrm{HI}$ & MI & MI & 23 & MI & $\mathrm{HI}$ & MI & MI & 39 & HI & HI & MI & $\mathrm{HI}$ & 55 & MI & HI & MI & MI \\
\hline 8 & LI & EI & MI & MI & 24 & MI & EI & MI & MI & 40 & HI & EI & MI & HI & 56 & MI & EI & MI & MI \\
\hline 9 & LI & LI & HI & MI & 25 & MI & LI & $\mathrm{HI}$ & MI & 41 & HI & LI & $\mathrm{HI}$ & $\mathrm{HI}$ & 57 & MI & LI & HI & MI \\
\hline 10 & LI & MI & HI & MI & 26 & MI & MI & $\mathrm{HI}$ & MI & 42 & $\mathrm{HI}$ & MI & $\mathrm{HI}$ & $\mathrm{HI}$ & 58 & MI & MI & HI & MI \\
\hline 11 & LI & HI & HI & MI & 27 & MI & HI & HI & HI & 43 & HI & HI & HI & $\mathrm{HI}$ & 59 & MI & HI & HI & HI \\
\hline 12 & LI & EI & HI & MI & 28 & MI & EI & HI & HI & 44 & $\mathrm{HI}$ & EI & $\mathrm{HI}$ & $\mathrm{HI}$ & 60 & MI & EI & HI & HI \\
\hline 13 & LI & LI & EI & MI & 29 & MI & LI & EI & $\mathrm{HI}$ & 45 & HI & LI & EI & HI & 61 & MI & LI & EI & $\mathrm{HI}$ \\
\hline 14 & LI & MI & EI & $\mathrm{HI}$ & 30 & MI & MI & EI & $\mathrm{HI}$ & 46 & $\mathrm{HI}$ & MI & EI & $\mathrm{HI}$ & 62 & MI & MI & EI & $\mathrm{HI}$ \\
\hline 15 & LI & $\mathrm{HI}$ & EI & HI & 31 & MI & $\mathrm{HI}$ & EI & $\mathrm{HI}$ & 47 & HI & $\mathrm{HI}$ & EI & HI & 63 & MI & HI & EI & $\mathrm{HI}$ \\
\hline 16 & LI & EI & EI & EI & 32 & MI & EI & EI & HI & 48 & HI & EI & EI & EI & 64 & MI & EI & EI & EI \\
\hline
\end{tabular}




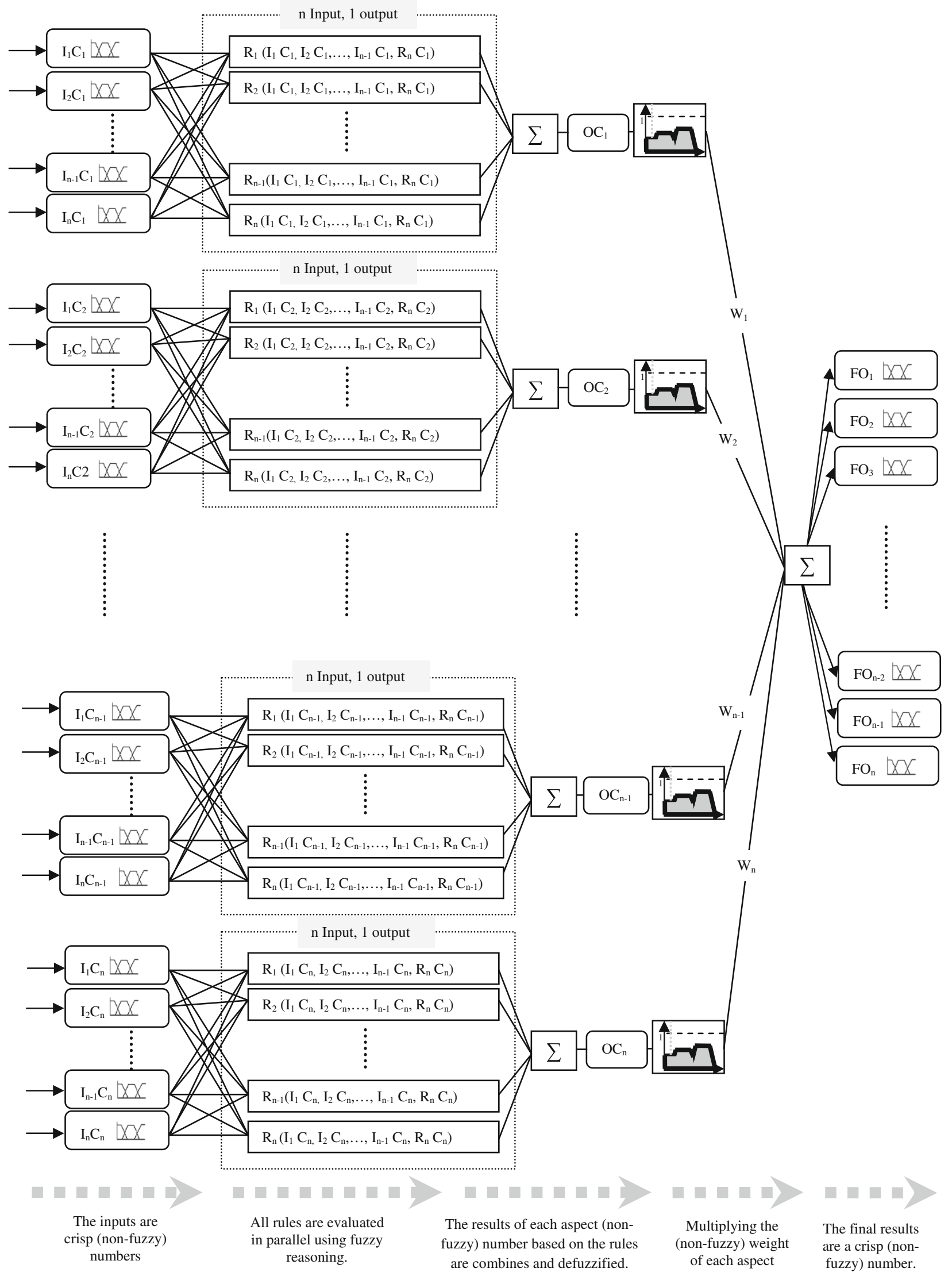

Fig. 6 The hierarchical model of supplier evaluation and selection 
fuzzy output criteria - the sum of the moment aspect values is multiplied by a weighting aspect. The formula can be expressed as:

Final result $=\frac{\sum_{i=0}^{n}\left(\frac{\int \mu_{i}(x) x \mathrm{~d} x}{\int \mu_{i}(x) \mathrm{d} x}\right) w_{i}}{\sum_{i=0}^{n} w_{i}}$

where $W_{i}$ represents aspect $i$, and $\mu_{i}(x)$ the aggregated membership function, and $x$ the output variable. Final supplier selection results are categorized in three

Table 9 List of the properties of attributes

\begin{tabular}{llll}
\hline No. & Fuzzy output variables & & Fuzzy input variables \\
\hline 1 & Trust $\left(A_{1}\right)$ & 1.1 & Inter-firm trust $\left(C_{11}\right)$ \\
& & 1.2 & Interpersonal trust $\left(C_{12}\right)$ \\
2 & Quality $\left(A_{2}\right)$ & 2.1 & Product $\left(C_{21}\right)$ \\
& & 2.2 & Manufacturing $\left(C_{22}\right)$ \\
3 & Cost $\left(A_{3}\right)$ & 3.1 & Direct cost $\left(C_{31}\right)$ \\
& & 3.2 & Indirect cost $\left(C_{32}\right)$ \\
4 & Delivery $\left(A_{4}\right)$ & 4.1 & Compliance with due time \\
& & 4.2 & Compliance with quality \\
& & & $\left(C_{42}\right)$ \\
& & 5.1 & Environment $\left(C_{51}\right)$ \\
5 & Management and & 5.2 & Performance history $\left(C_{52}\right)$ \\
& organization $\left(A_{5}\right)$ & 5.3 & Facility and technical \\
& & & capability $\left(C_{53}\right)$ \\
& & 6.1 & Manufacturing $\left(C_{61}\right)$ \\
6 & Financial $\left(A_{6}\right)$ & 6.2 & Product $\left(C_{62}\right)$
\end{tabular}

Table 10 The importance of the decision aspect

\begin{tabular}{lllllllllll}
\hline Aspects & $D_{1}$ & $D_{2}$ & $D_{3}$ & $D_{4}$ & $D_{5}$ & $D_{6}$ & $D_{7}$ & $D_{8}$ & $D_{9}$ & $D_{10}$ \\
\hline$A_{1}$ & $\mathrm{H}$ & $\mathrm{VH}$ & $\mathrm{M}$ & $\mathrm{VH}$ & $\mathrm{L}$ & $\mathrm{H}$ & $\mathrm{M}$ & $\mathrm{H}$ & $\mathrm{L}$ & $\mathrm{H}$ \\
$A_{2}$ & $\mathrm{M}$ & $\mathrm{H}$ & $\mathrm{M}$ & $\mathrm{M}$ & $\mathrm{VL}$ & $\mathrm{H}$ & $\mathrm{H}$ & $\mathrm{M}$ & $\mathrm{L}$ & $\mathrm{L}$ \\
$A_{3}$ & $\mathrm{VH}$ & $\mathrm{M}$ & $\mathrm{M}$ & $\mathrm{VH}$ & $\mathrm{M}$ & $\mathrm{M}$ & $\mathrm{H}$ & $\mathrm{L}$ & $\mathrm{M}$ & $\mathrm{M}$ \\
$A_{4}$ & $\mathrm{M}$ & $\mathrm{H}$ & $\mathrm{L}$ & $\mathrm{H}$ & $\mathrm{VL}$ & $\mathrm{L}$ & $\mathrm{M}$ & $\mathrm{H}$ & $\mathrm{L}$ & $\mathrm{L}$ \\
$A_{5}$ & $\mathrm{M}$ & $\mathrm{H}$ & $\mathrm{L}$ & $\mathrm{H}$ & $\mathrm{H}$ & $\mathrm{VL}$ & $\mathrm{L}$ & $\mathrm{L}$ & $\mathrm{L}$ & $\mathrm{M}$ \\
$A_{6}$ & $\mathrm{H}$ & $\mathrm{M}$ & $\mathrm{L}$ & $\mathrm{M}$ & $\mathrm{VH}$ & $\mathrm{VL}$ & $\mathrm{L}$ & $\mathrm{M}$ & $\mathrm{M}$ & $\mathrm{L}$ \\
\hline
\end{tabular}

classifications including weakly preferred if the score is in the range of 0-35\%, moderately preferred if the score is in the range of 30-70\%, and extremely preferred if the score is in the range of $65-100 \%$.

Description of the proposed model

Figure 6 illustrates a general supplier selection hierarchical model based on the properties of the attributes, including fuzzy input and output variables. All rules are evaluated in parallel using fuzzy reasoning. In the next step based on the rules, the results of each non-fuzzy number aspect is combined and defuzzified. Finally, the results are evaluated based on multiplying the non-fuzzy weight of each aspect and the values are assigned to each fuzzy output criteria.

\section{Illustrative example}

For verifying the model a test-bed is used (Silberholz and Golden 2010). Six aspects and thirteen criteria for supplier evaluation and selection model were collected based on the 28 literatures (Table 9). Based on these criteria and using FIS approach, the supplier selection model is established.

A committee of ten decision makers $D 1, D 2, D 3, \ldots$, $D 10$ utilize the weight to assess the importance of each aspect. Six aspects are considered: trust $\left(A_{1}\right)$, quality $\left(A_{2}\right)$, cost $\left(A_{3}\right)$, delivery $\left(A_{4}\right)$, management and organization $\left(A_{5}\right)$, and financial $\left(A_{6}\right)$. It uses a FDM to adjust the fuzzy weighting by every expert to achieve the consensus condition, which obtains the important weight of the criteria by using the ten decision-makers; it is shown as Table 10.

In the next steps, the opinions of experts in FDM questionnaires are converted to positive triangular fuzzy numbers. Finally, the aggregate fuzzy weights for each criterion are calculated by grouping the linguistic assessments of the ten decision-makers. The aggregate weights calculated by employing Eqs. 1, 2, 3 and 4, which are listed in the fuzzy, mean column of Table 11. Finally, center-ofarea defuzzification technique is applied to convert the fuzzy number into crisp real numbers. The value of fuzzy numbers can be obtained in the last column of Table 12.

Table 11 The average linguistic rating of aspects for supplier selection and evaluation model

\begin{tabular}{|c|c|c|c|c|c|c|c|}
\hline Aspects & $D_{1}$ & $D_{2}$ & $\ldots$ & $D_{9}$ & $D_{10}$ & Fuzzy mean $=\Sigma \mathrm{D}$ & Values \\
\hline$A_{1}$ & $(0.5,0.7,1.0)$ & $(0.7,1.0,1.0)$ & $\ldots$ & $(0.0,0.3,0.5)$ & $(0.5,0.7,1.0)$ & $W_{1}=(0.38,0.64,0.86)$ & 0.626 \\
\hline$A_{2}$ & $(0.2,0.5,0.8)$ & $(0.5,0.7,1.0)$ & $\ldots$ & $(0.0,0.3,0.5)$ & $(0.0,0.3,0.5)$ & $W_{2}=(0.22,0.47,0.75)$ & 0.480 \\
\hline$A_{3}$ & $(0.7,1.0,1.0)$ & $(0.2,0.5,0.8)$ & $\ldots$ & $(0.2,0.5,0.8)$ & $(0.2,0.5,0.8)$ & $W_{3}=(0.31,0.60,0.83)$ & 0.580 \\
\hline$A_{4}$ & $(0.5,0.7,1.0)$ & $(0.2,0.5,0.8)$ & $\ldots$ & $(0.2,0.5,0.8)$ & $(0.0,0.3,0.5)$ & $W_{4}=(0.20,0.46,0.70)$ & 0.453 \\
\hline$A_{5}$ & $(0.2,0.5,0.8)$ & $(0.5,0.7,1.0)$ & $\ldots$ & $(0.0,0.3,0.5)$ & $(0.0,0.3,0.5)$ & $W_{5}=(0.19,0.43,0.67)$ & 0.410 \\
\hline$A_{6}$ & $(0.2,0.5,0.8)$ & $(0.5,0.7,1.0)$ & $\ldots$ & $(0.0,0.3,0.5)$ & $(0.2,0.5,0.8)$ & $W_{6}=(0.19,0.38,0.66)$ & 0.430 \\
\hline
\end{tabular}


Table 12 Ranking fuzzy aspect based on the $\alpha$-cut set

\begin{tabular}{lll}
\hline Rank & Aspects & Values \\
\hline 1 & $A_{1}$ & $\mathrm{H}\left(A_{1}\right)=0.626$ \\
2 & $A_{3}$ & $\mathrm{H}\left(A_{3}\right)=0.580$ \\
3 & $A_{2}$ & $\mathrm{H}\left(A_{2}\right)=0.480$ \\
4 & $A_{4}$ & $\mathrm{H}\left(A_{4}\right)=0.453$ \\
5 & $A_{6}$ & $\mathrm{H}\left(A_{6}\right)=0.430$ \\
6 & $A_{5}$ & $\mathrm{H}\left(A_{5}\right)=0.410$ \\
\hline
\end{tabular}

The six aspects ranking are representative and have been studied by many scholars. The six fuzzy numbers based on six aspects are ranked as it is shown in Table 11: $A_{5} \prec A_{6} \prec A_{4} \prec A_{2} \prec A_{3} \prec A_{1}$.

According to Table 13, the Mamdani fuzzy inference, which is based on an implied function minimum operator (min) and aggregation function maximum $(\max )$ will be used for conjunction operator. The membership value of the control action of each rule is the minimum value of the input variable's membership values.

The rule numbers of two, three input criteria of six aspects are as follows: $\alpha$ rule will be used for two-input criteria $\left(N_{2}^{\alpha}=4^{2}\right)$; and $\beta$ rule will be used for three-input criteria $\left(N_{2}^{\beta}=4^{3}\right)$.

For the sample, trust $\left(A_{1}\right)$ output criteria have two input variables included "Interfirm trust $\left(\mathrm{C}_{11}\right)$ ", and "Interpersonal trust $\left(\mathrm{C}_{12}\right)$ ". These input variables have been used as two trapezoid membership function as shown in Table 12 and Fig. 7. The next step is the formulation of the FLs. This collection of FLs approximately represents the human thinking in the decision-making process. These rules in the

Table 13 Summary of the basic fuzzy rule based system

\begin{tabular}{|c|c|c|c|c|c|c|c|c|}
\hline $\begin{array}{l}\text { No. } \\
\text { aspect }\end{array}$ & Aspect name & $\begin{array}{l}\text { No. of } \\
\text { inputs }\end{array}$ & $\begin{array}{l}\text { Rule } \\
\text { name }\end{array}$ & $\begin{array}{l}\text { No. of } \\
\text { rules }\end{array}$ & $\begin{array}{l}\text { No. of } \\
\text { outputs }\end{array}$ & $\begin{array}{l}\text { Conjunction } \\
\text { operator }\end{array}$ & $\begin{array}{l}\text { Aggregation } \\
\text { operator }\end{array}$ & $\begin{array}{l}\text { Inference } \\
\text { model }\end{array}$ \\
\hline 1 & Trust & 2 & $\alpha$ & 16 & 1 & Min & $\operatorname{Max}$ & Mandani \\
\hline 2 & Quality & 2 & $\alpha$ & 16 & 1 & Min & $\operatorname{Max}$ & Mandani \\
\hline 3 & Cost & 2 & $\alpha$ & 16 & 1 & Min & $\operatorname{Max}$ & Mandani \\
\hline 4 & Delivery & 2 & $\alpha$ & 16 & 1 & Min & $\operatorname{Max}$ & Mandani \\
\hline 5 & $\begin{array}{c}\text { Management and } \\
\text { organization }\end{array}$ & 3 & $\beta$ & 64 & 1 & Min & $\operatorname{Max}$ & Mandani \\
\hline 6 & Financial & 2 & $\alpha$ & 16 & 1 & Min & $\operatorname{Max}$ & Mandani \\
\hline
\end{tabular}

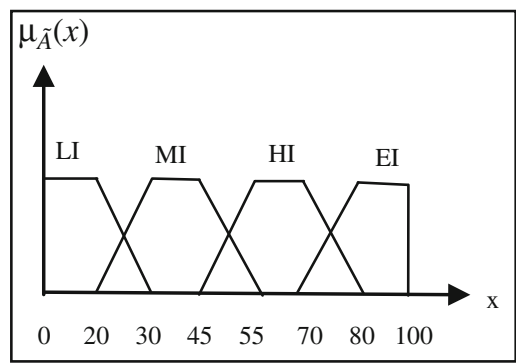

Input (1): Interfirm trust
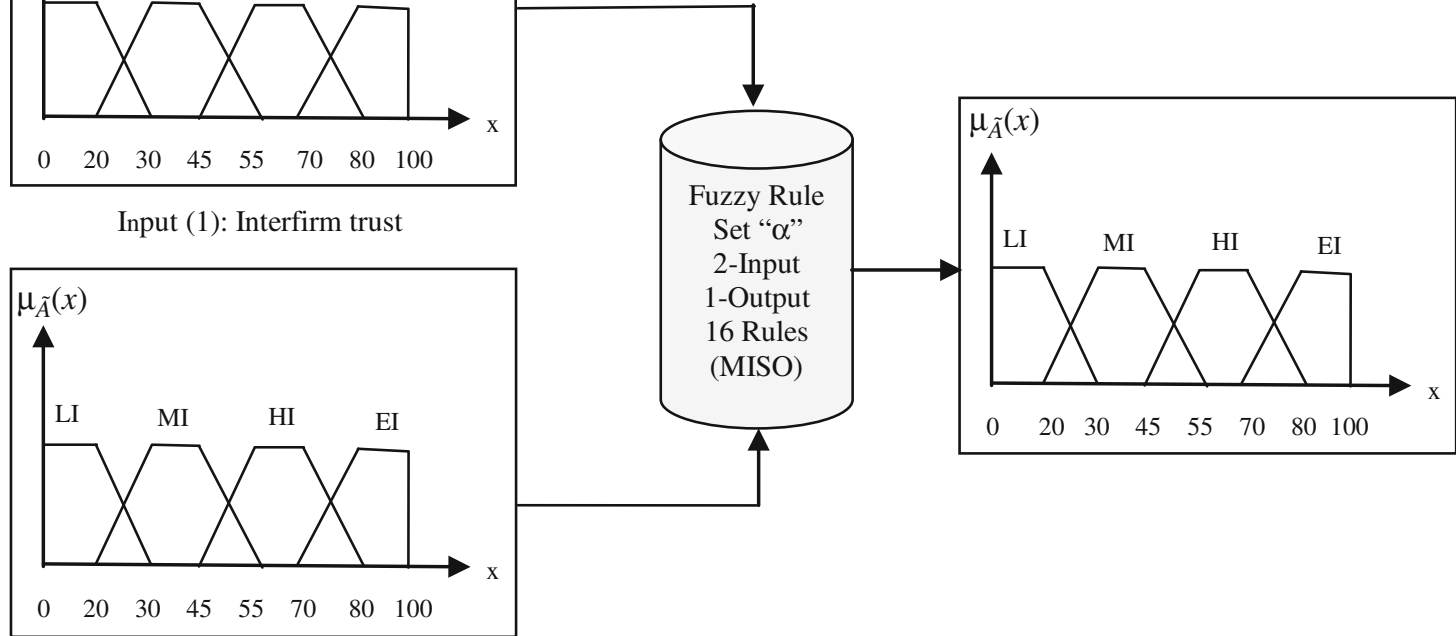

Input (2): Interpersonal trust

Fig. 7 Multifactor fuzzy inference system for strategy (output 1) aspect 
Fig. 8 The trust $\left(A_{1}\right)$ rule viewer of the FIS

Fig. 9 The output surface of the FIS for the case of example
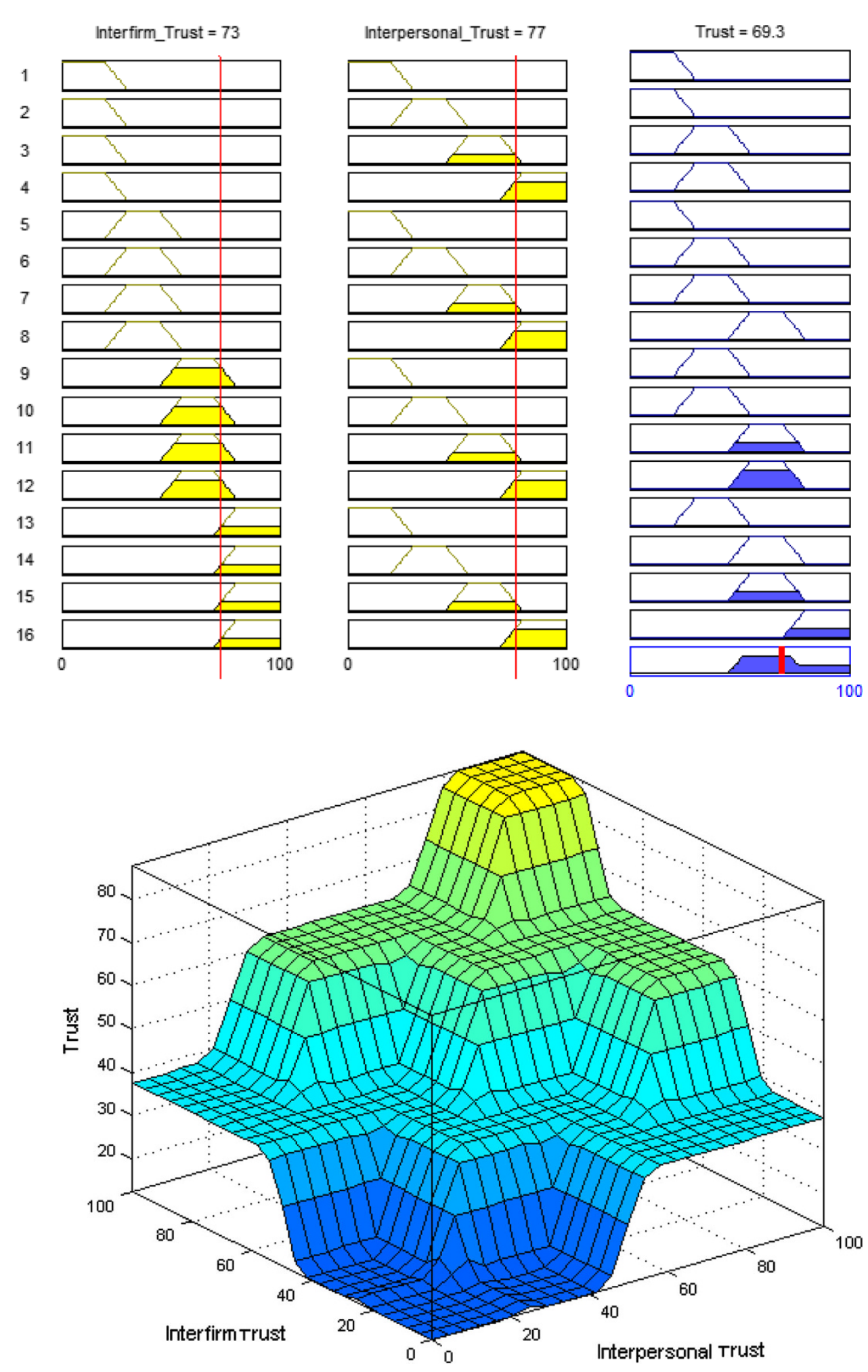

case of multi-input-single-output systems (MISO) are designed based on the input number variable. Rules are presented in Tables 6 and 7. Table 7 illustrates a sample of the generated FLs $(\alpha=16)$ for trust aspect with two input variables.
Figure 7 , shows the fuzzy sets inputs $\left(C_{11}\right)$, and $\left(C_{12}\right)$ after implication. In the next step, all output decisions are based on testing all rules in a FIS. The rules $\left(R_{i}\right)$ must be combined in some manner in order to make a decision. The aggregation operation is used to calculate the combined 
Table 14 Final score of supplier "F" evaluation

\begin{tabular}{|c|c|c|c|c|c|c|}
\hline \multicolumn{2}{|c|}{ Fuzzy input } & \multicolumn{2}{|c|}{ Fuzzy output } & \multicolumn{2}{|c|}{ Weight of aspect } & \multirow[t]{2}{*}{ Overal } \\
\hline Name & Value & Name & Value & Name & Value & \\
\hline$C_{11}$ & 73 & \multirow{2}{*}{$A_{1}$} & \multirow[t]{2}{*}{69.3} & \multirow[t]{2}{*}{$\mathrm{WA}_{1}$} & \multirow[t]{2}{*}{0.626} & \multirow[t]{2}{*}{43.38} \\
\hline$C_{12}$ & 77 & & & & & \\
\hline$C_{21}$ & 79 & \multirow[t]{2}{*}{$A_{2}$} & \multirow[t]{2}{*}{76.4} & \multirow[t]{2}{*}{$\mathrm{WA}_{2}$} & \multirow[t]{2}{*}{0.480} & \multirow[t]{2}{*}{36.67} \\
\hline$C_{22}$ & 83 & & & & & \\
\hline$C_{31}$ & 86 & \multirow[t]{2}{*}{$A_{3}$} & \multirow[t]{2}{*}{87.6} & \multirow[t]{2}{*}{$\mathrm{WA}_{3}$} & \multirow[t]{2}{*}{0.580} & \multirow[t]{2}{*}{50.80} \\
\hline$C_{32}$ & 82 & & & & & \\
\hline$C_{41}$ & 80 & \multirow[t]{2}{*}{$A_{4}$} & \multirow[t]{2}{*}{87.6} & \multirow[t]{2}{*}{$\mathrm{WA}_{4}$} & \multirow[t]{2}{*}{0.453} & \multirow[t]{2}{*}{39.68} \\
\hline$C_{42}$ & 85 & & & & & \\
\hline$C_{51}$ & 74 & \multirow[t]{3}{*}{$A_{5}$} & \multirow[t]{3}{*}{86.6} & \multirow[t]{3}{*}{$\mathrm{WA}_{5}$} & \multirow[t]{3}{*}{0.410} & \multirow[t]{3}{*}{35.50} \\
\hline$C_{52}$ & 84 & & & & & \\
\hline$C_{53}$ & 84 & & & & & \\
\hline$C_{61}$ & 85 & \multirow[t]{2}{*}{$A_{6}$} & \multirow[t]{2}{*}{87.6} & \multirow[t]{2}{*}{$\mathrm{WA}_{6}$} & \multirow[t]{2}{*}{0.430} & \multirow[t]{2}{*}{37.66} \\
\hline$C_{62}$ & 89 & & & & & \\
\hline \multicolumn{6}{|c|}{ Final result of supplier selection $=81.81 \%$} & \\
\hline
\end{tabular}

fuzzy set outputs of each rule into a single fuzzy set. The output of the aggregation process is one fuzzy set for each output variable.

To show the structure of rule viewers in the model, which presents the road maps of FIS systems, trust one rule viewer of the FIS is chosen as an example. Figure 8 illustrates the rule viewer of the related FIS of trust variable. Each rule is a row of plots and each column is a variable. Interfirm trust $(C 11)$ and interpersonal trust $(C 12)$ are applied as input variables and trust $(A 1)$ as an output variable or aspect. Having verified the rules, 16 in number, which are obtained from the input number of each aspect " 2 ", it will be evident that the output value (trust) increases similar to the results of the input values [interfirm trust (C11) and interpersonal trust $(C 12)]$. Three rules which have been placed together to show the combination and aggregation of each rule into a single fuzzy set value "output $\left(A_{1}\right)=69.3$ " are illustrated in Fig. 8. Finally, these fuzzy outputs need to be converted into a scalar output quantity so that the nature of the action to be performed can be determined by the center of gravity method as illustrated in Eq. 12.

The output surface of the related FIS of "trust" $\left(A_{1}\right)$ is shown in Fig. 9. Two input variables [interfirm trust $\left(C_{11}\right)$ and interpersonal trust $\left(C_{12}\right)$ ] and one output variable [trust $\left(A_{1}\right)$ ] varies between 0 and 100 . It can be seen that as the input values of interfirm trust $\left(C_{11}\right)$ and interpersonal trust $\left(C_{12}\right)$ are increased, the output value of the trust of success in supplier selection is also increased.

Finally, using the obtained FD weights for each aspect and each fuzzy rule of the corresponding fuzzy output criterion, the overall rate is calculated based on the Eq. 13 . Table 14 illustrates the name and value of Fuzzy input and output weight of each aspect for supplier " $F$ ". The overall score for supplier "F" obtained from each aspect is shown in the last column. The final result of supplier " $F$ " is $81.81 \%$ which is in the extremely preferred $(65,70$, $100,100)$ area. This procedure is done for other suppliers as
Table 15 Final score and ranking of 12 suppliers

\begin{tabular}{|c|c|c|c|c|c|c|c|c|}
\hline & \multicolumn{6}{|c|}{ Overall } & \multirow{2}{*}{$\begin{array}{l}\text { Final } \\
\text { score }(\%)\end{array}$} & \multirow[t]{2}{*}{ Ranking } \\
\hline & $A_{1}$ & $A_{2}$ & $A_{3}$ & $A_{4}$ & $A_{5}$ & $A_{6}$ & & \\
\hline Supplier (A) & 20.66 & 18 & 7.59 & 14.54 & 13.36 & 5.33 & 26.68 & 11 \\
\hline Supplier (B) & 49.45 & 33.26 & 49.01 & 34.60 & 30.01 & 31.82 & 76.59 & 3 \\
\hline Supplier (C) & 23.47 & 22.12 & 21.75 & 16.98 & 13.36 & 23.47 & 40.67 & 7 \\
\hline Supplier (D) & 21.72 & 18 & 16.47 & 12.86 & 17.63 & 13.80 & 33.73 & 9 \\
\hline Supplier (E) & 8.20 & 18 & 19.14 & 15.71 & 12.34 & 13.80 & 29.27 & 10 \\
\hline Supplier (F) & 43.38 & 36.67 & 50.80 & 39.68 & 35.50 & 37.66 & 81.81 & 1 \\
\hline Supplier (G) & 8.20 & 7.44 & 7.83 & 5.61 & 15.37 & 14.19 & 19.68 & 12 \\
\hline Supplier $(\mathrm{H})$ & 47.82 & 30 & 42.92 & 37.01 & 27.71 & 26.87 & 71.28 & 4 \\
\hline Supplier (I) & 51.14 & 30 & 49.1 & 35.78 & 35.13 & 37.66 & 80.14 & 2 \\
\hline Supplier (J) & 20.65 & 30 & 64.62 & 33.52 & 30.13 & 23.73 & 57.94 & 6 \\
\hline Supplier (K) & 39.12 & 33.55 & 36.25 & 28.31 & 28.41 & 29.79 & 65.60 & 5 \\
\hline Supplier (L) & 23.47 & 15.84 & 33.75 & 14.90 & 12.34 & 16.12 & 39.08 & 8 \\
\hline
\end{tabular}

Table 16 Ranking and evaluating the suppliers based on weakly, moderately, and extremely preferred

\begin{tabular}{lll}
\hline Weakly preferred & Moderately preferred & Extremely preferred \\
\hline $\mathrm{S}_{3}(\mathrm{G})<\mathrm{S}_{2}(\mathrm{~A})<\mathrm{S}_{1}(\mathrm{E})$ & $\mathrm{S}_{5}(\mathrm{D})<\mathrm{S}_{4}(\mathrm{~L})<\mathrm{S}_{3}(\mathrm{C})<\mathrm{S}_{2}(\mathrm{~J})<\mathrm{S}_{1}(\mathrm{~K})$ & $\mathrm{S}_{4}(\mathrm{H})<\mathrm{S}_{3}(\mathrm{~B})<\mathrm{S}_{2}(\mathrm{I})<\mathrm{S}_{1}(\mathrm{~F})$ \\
\hline
\end{tabular}


well as shown in Table 15. Table 16 shows the ranking of suppliers in each classification based on "extremely preferred", "moderately preferred", and "weakly preferred" categories.

\section{Conclusion}

The main contribution of this paper is the identification of the important criteria for selecting and evaluating the best supplier. The six aspects and thirteen criteria for supplier selection model are proposed. The six aspects are including trust, quality, cost, delivery, management and organization, financial; in which "trust" and "cost" are ranked as the top two aspects. The second contribution is the development of a multi-criteria decision making model for evaluating the criteria and selecting the appropriate supplier. This model is successfully developed by integrating the FDM and FIS methods. The rules for FIS are designed based on the number of input variables of each aspect. The number of rules for each aspect, is calculated separately based on each rule name including $\alpha, \beta$. $\alpha$ has $16, \beta$ has 64 , which together, there are 80 rules. Finally, the developed model is tested based on numerical test bed example with 12 suppliers. The results confirmed the model feasibility and ability to assist decision makers for examining the strengths and weaknesses of supplier by comparing them with appropriate aspects and criteria.

Acknowledgment The authors would like to acknowledge the financial support provided by the Malaysian Ministry of Higher Education (MOHE) under the High Impact Research Grant (Grant No. UM.C/HIR/MOHE/ENG/35 (D000035- 16001)).

Open Access This article is distributed under the terms of the Creative Commons Attribution License which permits any use, distribution, and reproduction in any medium, provided the original author(s) and the source are credited.

\section{References}

Ahire SL, Golhar DY, Waller MA (1996) Development and validation of TQM implementation constructs. Decis Sci 27(1):23-56

Aktepe A, Ersoz S (2011) A fuzzy analytic hierarchy process model for supplier selection and a case study. Int J Res Dev 3(1):33-37

Amindoust A, Ahmed S, Saghafinia A, Bahreininejad A (2012) Sustainable supplier selection: a ranking model based on fuzzy inference system. Appl Soft Comput 12(6):1668-1677

AydIn Keskin G, Ihan S, Özkan C (2010) The fuzzy art algorithm: a categorization method for supplier evaluation and selection. Expert Syst Appl 37:1235-1240

Baetge J, Heitmann C (2000) Creating a fuzzy rule-based indicator for the review of credit standing. SBR 52(4):318-343

Bello MJS (2003) A case study approach to the supplier selection process. Master of engineering in Management Systems Engineering, University of Puerto rico, Mayaguez Campus
Benyoucef L, Ding H, Xie X (2003) Supplier selection problem: selection criteria and methods. INRIA, Rapport de recherche no. 4726

Bhattacharya A, Geraghty J, Young P (2010) Supplier selection paradigm: an integrated hierarchical QFD methodology under multiple-criteria environment. Appl Soft Comput 10:1013-1027

Bross ME, Zhao G (2004) Supplier selection process in emerging markets - the case study of Volvo Bus Corporation in China. Master Thesis, School of Economics and Commercial Law, Göteborg University

Buyukozkan G, Cifci G (2010) A novel fuzzy multi-criteria decision framework for sustainable supplier selection with incomplete information, Computers in Industry

Chan FTS, Kumar N (2007) Global supplier development considering risk factors using fuzzy extended AHP-based approach. Omega $35: 417-431$

Chen-Tung C, Ching-Torng L (2006) A fuzzy approach for supplier evaluation and selection in supply chain management. Prod Econ 102:289-301

Cheng JH, Tang CH (2009) An application of fuzzy Delphi and fuzzy AHP for multi-criteria evaluation on bicycle industry supply chains. WSEAS Trans Syst Control 4(1):21-34

Dickson GW (1966) An analysis of vendor selection systems and decisions. J Purch 2(1):5-17

Dulmin R, Mininno V (2003) Supplier selection using a multi-criteria decision aid method. J Purch Suppl Manag 9:177-187

Dyer JH, Cho DS, Chu W (1996) Strategic supplier segmentation: a model for managing suppliers in the 21 st centery. University of Pemsylvania, Philadelphia

Ghodsypour SH, O'Brien C (1998) A decision support system for supplier selection using an integrated analytical hierarchy process and linear programming. Int J Prod Econ 56-67:199-212

Handfield R, Walton SV, Sroufe R (2002) Applying environmental criteria to supplier assessment: a study in the application of the analytical hierarchy process. Eur J Oper Res 141:70-87

Ho W, Xu X, Dey PK (2010) Multi-criteria decision making approaches for supplier evaluation and selection: a literature review. Eur J Oper Res 202:16-24

Hsu YL (2010) The application of fuzzy Delphi method and fuzzy AHP in lubricant regenerative technology selection. Expert Syst Appl 37:419-425

Ishikawa AA (1993) The max-min Delphi method and fuzzy Delphi method via fuzzy integration. Fuzzy Sets Syst 55:241-253

Junior FRL, Osiro L, Carpinetti LCR (2013) A fuzzy inference and categorization approach for supplier selection using compensatory and non-compensatory decision rules. Appl Soft Comput 13(10):4133-4147

Keufmann AG (1991) Introduction to fuzzy arithmetic: theory and application. Van Nostrand Reinhold, New York

Kheljani JG, Ghodsypour SH, O'Brien C (2009) Optimizing whole supply chain benefit versus buyer's benefit through supplier selection. Int J Prod Econ 121:482-493

Lin CT, Chen CB, Ting YC (2011) An ERP model for supplier selection in electronics industry. Expert Syst Appl 38:1760-1765

Liu FHF, Hai HL (2005) The voting analytic hierarchy process method for selecting supplier. Int J Prod Econ 97(3):308-317

Mafakheri F, Breton M, Ghoniem A (2011) Supplier selection-order allocation: a two stage multiple criteria dynamic programming approach, Int J Prod Econ 132(1):52-57

Maani KE (1989) Productivity and profitability through quality-myth and reality. Int J Qual Reliab Manag 6(3):11-23

Milgate M (2001) Supply chain complexity and delivery performance: an international exploratory study. Supply Chain Manag Int J 6:106-118

Moghadam MRS, Afsar A, Sohrabi B (2008) Inventory lot-sizing with supplier selection using a hybrid intelligent algorithm. Appl Soft Comput 8:1523-1529 
Noorderhaben N (1995) Strategic decision making. Addison-Wesley, UK

Ordoobadi SM (2009) Development of a supplier selection model using fuzzy logic. Supply Chain Manage Int J 14:314-327

Przewosnik D, Smeja I, Tenschertet U (2006) Supplier selection-a study of the supplier selection process within the sporting goods manufacturing industry. Master Thesis: Master Program in Logistics Management. School of Management and Economics (Vaxjo)

Shen C, Yu K (2009) Enhancing the efficacy of supplier selection decision-making on the initial stage of new product development: a hybrid fuzzy approach considering the strategic and operational factors simultaneously. Expert Syst Appl 36:11271-11281

Silberholz J, Golden B (2010) Comparison of metaheuristics. In Handbook of Metaheuristics, Springer

Tahriri F, Taha Z (2010) The concept of integrating virtual group (VG) and agile supplier selection (ASS). J Bus Manage Econ 1(1):032-037

Tahriri F, Osman MR, Ali A, Rosnah Md Y, Esfandyari AR (2008a) AHP approach for supplier evaluation and selection in a steel manufacturing company. J Ind Eng Manag 1(2):54-76

Tahriri F, Osman Md R, Ali A (2008b) A review of supplier selection methods in manufacturing industries. Suranaree J Sci Technol 15(3):201-208

Tam MCY, Tummala VMR (2001) An application of the AHP in vendor selection of a telecommunications system. Omega 29(2):171-182
Wang MLH (2008) To construct a monitoring mechanism of production loss by using fuzzy Delphi methods and fuzzy regression technique - a case study of the IC package testing company. Expert Syst Appl 35:1156-1165

Wang JW, Cheng CH, Kun-Cheng H (2009) Fuzzy hierarchical TOPSIS for supplier selection. Appl Soft Comput 9:377-386

Weber CA, Current JR, Benton WC (1991) Vendor selection criteria and methods. Eur J Oper Res 50:2-18

Wu DS, Olson DL (2008) Supply chain risk, simulation, and vendor selection. Int J Prod Econ 114:646-655

Yahya S, Kingsman B (1999) Vendor rating for an entrepreneur development programme: a case study using the analytic hierarchy process method. J Oper Res Soc 50:916-930

Yu-Feng HHL (2008) Applying fuzzy Delphi method to select the variables of a sustainable urban system dynamics model. In: Proceeding of the 2008 international conference of the System Dynamics Society July 20-24, Athens, Greece

Yu X, Jing S (2004) A decision model for supplier selection considering trust. Chin Bus Rev 3(6):15-20

Yusuff Rd, PohYee K, Hashmi MSJ (2001) A preliminary study on the potential use of the analytical hierarchical process (AHP) to predict advanced manufacturing technology (AMT) implementation. Robot Comput Integr Manuf 17:421-427

Zadeh L (1975) The concept of a linguistic variable and its application to approximate reasoning-I 8:199-249

Zhang Z, Lei J, Cao N, To K, Ng K (2003) Evolution of supplier selection criteria and methods. Eur J Oper Res 4(1):335-342 